\title{
Pengembangan Perumahan Produktif Berbasis Wisata di Kawasan Industri Phinisi Kabupaten Bulukumba
}

\author{
Andi Ahmad Fauzan Bachtiar*1 ${ }^{1}$, Shirly Wunas ${ }^{2}$, Mimi Arifin ${ }^{3}$ \\ ${ }^{1}$ Departemen Teknik Arsitektur, Fakultas Teknik, Universitas Hasanuddin, Makassar \\ Jl. Poros Malino Km.6, Bontomarannu, Gowa, Sulawesi Selatan, 92171, Indonesia \\ *Email: andiaan01@ gmail.com
}

\begin{abstract}
Abstrak
Penelitian ini bertujuan untuk (1) Menganalisis karakteristik perumahan dan lingkungan pengrajin kapal phinisi berbasis wisata pada Kawasan Industri Pembuatan Kapal Phinisi yang berada di Tanahberu Kabupaten Bulukumba, (2) Menganalisis perkembangan perumahan produktif yang berbasis wisata terhadap kegiatan-kegiatan pada kawasan pembuatan kapal phinisi, (3) Menyusun konsep penataan kawasan perumahan pengrajin kapal phinisi dan lingkungan yang produktif serta berbasis wisata pada kawasan industri pembuatan kapal phinisi. Data yang digunakan berasal dari 162 responden yang bermukim di kawasan industri pembuatan kapal phinisi, yang dilakukan secara Simple random sampling, probability sampling. Menggunakan kuesioner dan wawancara mendalam. Analisis dilakukan secara deskriptif kualitataif, dan secara eksploratif. Hasil penelitian menunjukkan 1) Perumahan pekerja kapal phinisi dominan dalam bentuk rumah panggung, dengan ciri Bugis Makassar. 2) Perumahan Produktif tidak dominan (51,9\%) karena masyarakat di Kawasan Industri Kapal Phinisi mempergunakan halaman rumah sebagai ruang untuk usaha. Kegiatan yang dapat menunjang wisata dari aspek barang yang dapat dibeli adalah berupa souvenir yang terbuat dari sisa material kayu pembuatan kapal phinisi. Kegiatan wisata dari aspek yang dapat dilihat adalah pembuatan kapal phinisi, dan mengunjungi replika kapal di area pembuatan kapal phinisi. 3) Penataan kawasan mempergunakan konsep revitalisasi terhadap tapak bangunan, akses, dan landsekap unit kapling.
\end{abstract}

\begin{abstract}
Demand for productive home in tourist attractions is increasing day, by day, but over time some of those tourist attractions are neglected, such as phinisi shipbuilding industrial area in Tanahberu, Bulukumba. It makes the tourists do not consider some aspects to visit that place. This research aims to analyse the characteristic of the residentalof the Phinisi's craftsmen and its environment based on tourism in Phinisi Shipbuilding Industrial Area in Tanahberu, Bulukumba. The data use is from 162 respondents who live in the area of Phinisi Shipbuilding Industrial Area and is done with Simple Random Sampling, Probability Sampling, by questioner and interview. It is analysed by using descriptive qualitative. The result of this research shows that the characteristic of the residential of phinisi's craftsmen is dominated by house on stilts with Buginese-Makassar characteristic. Of 162 samples, it shows that 26.5\% house in Phinisi Shipbuilding Industrial Area are houses in stilts, while 21,6\% are common house, and the rest for arround 51,9\% are two stories houses with its pit buided.
\end{abstract}

Kata Kunci : Kawasan Wisata, Perumahan, Industri Phinisi

\section{Pendahuluan}

Pada umumnya kota pantai belum dieksplorasi dan dieksploitasi secara maksimal, biasanya hanya dipakai sebagai kawasan rekreasi, hiburan dan tempat mencari nafkah [1]. Keindahan pesisir pantai secara susitainable dapat dioptimalkan melalui ruang terbuka public yang berfungsi sosial $[2,3]$. yaitu ruang terbuka hijau (RTH), ruang kuliner, dan PK5. RTH yang dikembangkan sebaiknya dalam bentuk taman, halaman, hutan kota, dan jalur hijau [3]. Iklim dan cuaca pada kota pesisir pantai terasa panas dan lembab.
Vegetasi yang keragamannya semakin berkurang, berpengaruh terhadap kondisi lingkungan [4].

Bangunan pesisir pantai agar mempertimbangkan arah sinar matahari, arah angin, ukuran jendela dan ventilasi, dengan mempergunakan oversteck dan kanopy serta vegetasi dan ruang terbuka publik. Dapat memanfaatkan alam sesuai kearifan lokal, eksploitasi, tidak berlebihan agar dapat mencegah kerusakan fungsi lingkungan [5].

Ada berbagai suku yang kehidupannya sangat intim dengan laut dan pesisir pantai, misalnya suku Bugis-Makassar, di Sulawesi Selatan. Perahu 
dengan berbagai jenis ukuran, merupakan alat transportasi laut mereka yang digunakan secara turun temurun [6]. Perahu berukuran besar dikenal dengan nama Phinisi, sejak abad XVI dan XVII telah memiliki kemampuan jelajah sampai ke Filipina dan Kamboja. Phinisi secara turun temurun dibuat di Tanah Beru Kecamatan Bontobahari Kabupaten Bulukumba.

Oleh karena itu, Kabupaten Bulukumba dikenal dengan julukan Butta Panrita Lopi [7]. Di area lokasi sentra pengrajin phinisi semua rumpun keluarga melakukan pekerjaan sebagai pembuat kapal phinisi, dan hal ini juga merupakan sebagai mata pencaharian utama mereka [8].

Bentuk alat pelayaran yang pertama kali dipakai adalah model jenis perahu yang dibuat dari sebuah batang pohon dan dipotong mirip kayak model lesung. Untuk pembuatannya harus memakai kayu pilihan. Memotong kayu semacam itu kelihatannya sangat sederhana tetapi sulit sekali butuh keterampilan khusus dan pengalaman serta pengetahuan yang luas. Orang bugis menamakannya dengan sebutan Lepa-lepa atau biasa juga disebut sampan [9].

Keterampilan dan keahlian yang dimiliki oleh punggawa dan para pekerja kapal yang berada di kawasan pembuatan kapal phinisi di Tanah Beru Bulukumba merupakan keterampilan yang diperoleh sejak turun temurun. Diperoleh melalui pendidikan seumur hidup, yang diwariskan dari generasi ke generasi, sesuai dengan kebutuhan [10].

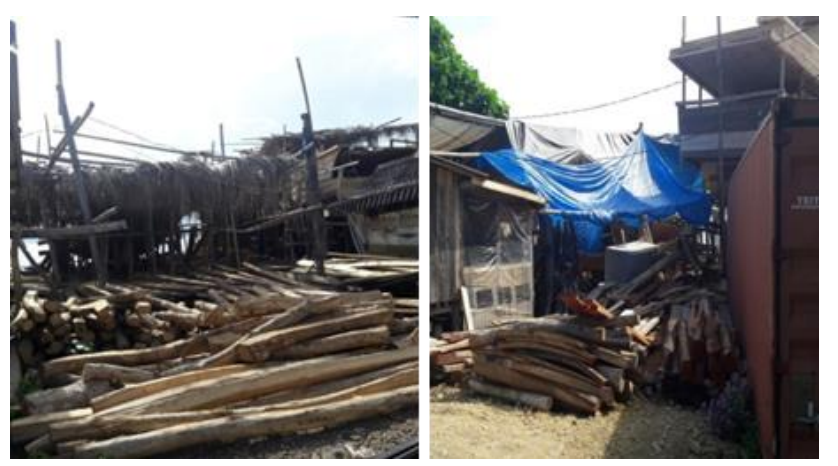

Gambar 1. Jenis-jenis kayu yang akan digunakan pengrajin phinisi

Kawasan pembuatan kapal tradisional Phinisi merupakan kawasan wisata bahari $[8,11]$. Kawasan tersebut telah menjadi kawasan wisata yang berpotensi untuk berkembang [10].
Tabel 1. Jumlah wisatawan yang berkunjung ke kawasan industri phinisi

\begin{tabular}{lccc}
\hline \multirow{2}{*}{ Kawasan } & \multicolumn{3}{c}{ Tahun } \\
\cline { 2 - 4 } & $\mathbf{2 0 0 6}$ & $\mathbf{2 0 1 1}$ & $\mathbf{2 0 1 6}$ \\
\hline Sapolohe & 1043 orang & 1567 orang & 2081 orang \\
Tanah Beru & 1043 orang & 1567 orang & 2081 orang \\
Tanah Lemo & 1043 orang & 1567 orang & 2081 orang \\
\hline Sumber: Kantor Camat Bontobahari
\end{tabular}

Potensi ini terlihat dari seringnya wisatawan lokal, maupun asing berkunjung walaupun hanya untuk sekedar melihat dan berfoto di lokasi tersebut. Adapun waktu yang digunakan untuk membuat kapal phinisi ini antara 6 sampai dengan 13 bulan. Dalam memproduksi kapal phinisi, para pengrajin melakukannya sesuai dengan kebiasaan yang telah diturunkan oleh leluhurnya [12]. Secara tradisional, baik dalam hal desain, waktu pengerjaan, pengadaan material dan harga, semuanya sesuai dengan kebiasaan lama tersebut [11]. Dari klasifikasi bentuk atap pada rumah tradisional yang berada dalam kawasan industri pembuatan kapal phinisi terdapat kesempurnaan yang dilihat dari kompleksitas struktur, teknik pengerjaan, jumlah material dan biaya yang dibutuhkan [13].

Pembangunan perumahan sudah seharusnya dapat mengutamakan faktor kemanusiaan, untuk dapat mewujudkan dan menciptakan perumahan yang nyaman, layak huni, memenuhi standar kesehatan lingkungan, aman juga menunjang pembangunan ekonomi, social, dan budaya masyarakat [14]. Pada tingkat atasnya, rumah harus bisa menciptakan rasa aman, sebagai tempat untuk menjalankan kegiatan ritual, penyimpanan harta milik yang berharga, menjamin hak pribadi [15].

Rumah tak lagi cukup untuk hidup, tetapi sudah menyumbang pengembangan pribadi bagi setiap penghuninya, melalui hobby, minat, dan perilaku lainnya [16]. Rumah dan lingkungan adalah suatu ekspresi/ pendapat masyarakat tentang budaya, termasuk didalamnya, agama, keluarga, struktur sosial dan hubungan antar individu yang menyangkut satu sama lain di daerah tersebut [17]. Secara Antropologis, bentuk rumah hunian dikelompokan kedalam tiga jenis, yaitu: rumah yang setengah dibawah tanah (semisubterranian dwelling), rumah diatas tanah 
(surface dwelling), rumah diatas tiang (pile dwelling)[18].

Rumah tradisional memiliki karakter yang spesifik meliputi bentuk dan desain yang menyesuaikan iklim daerah setempat, adanya ornamen tradisional, dan juga menggunakan material lokal [19]. Secara keseluruhan bentuk rumah tradisional sangat adaptif terhadap kondisi iklim pantai yang ada disekitarnya dan bencana yang terjadi, namun tuntutan ekspansi rumah dengan keterbatasan kemampuan konstruksi berdampak pada rendahnya keamanan dan keselamatan bangunan [20].

Maka dapat simpulkan bahwa perumahan tradisional terbentuk karena disebabkan oleh interaksi aspek fisik (shalter) dan aspek non fisik (budaya, agama, sosial) terbentuknya tradisional suatu kawasan dipengaruhi oleh interaksi aspek nonfisik (budaya, agama, sosial, gaya hidup) dalam kesatuan budaya secara keseluruhan untuk mempertahankan anggota keluarganya [21].

Tujuan Penelitian ini adalah (1) Menganalisis karakteristik perumahan dan lingkungan pengrajin kapal phinisi yang berbasis wisata pada Kawasan Industri Pembuatan Kapal phinisi, di Tanahberu Kabupaten Bulukumba, (2) Menganalisis perkembangan perumahan produktif yang berbasis wisata bahari terhadap kegiatan-kegiatan pada kawasan pembuatan kapal phinisi. (3) Menyusun konsep penataan kawasan perumahan dan lingkungan pengrajin kapal phinisi yang berbasis wisata pada kawasan industri pembuatan perahu phinisi.

\section{Metode}

\subsection{Jenis Penelitian}

Jenis Penelitian yang digunakan yaitu deskriptif-kualitatif, dan analisis komparatif serta metode yang dipergunakan adalah metode eksploratif dimana penelitian ini menganalisis karakteristik perumahan dan lingkungan kawasan industri pembuatan kapal phinisi.

\subsection{Lokasi dan Waktu Penelitian}

Lokasi penelitian berada di kawasan industri pembuatan kapal phinisi di Kecamatan Bontobahari Kabupaten Bulukumba. Lokasi dipilih karena berada di jalur poros Bulukumba-
Selayar, dan dekat dengan tempat wisata lainnya yang ada di Bulukumba, misal Pantai Bira, Pantai Bara, dan berbagai tempat wisata lainnya, yang berlangsung pada bulan Juni - September 2017.

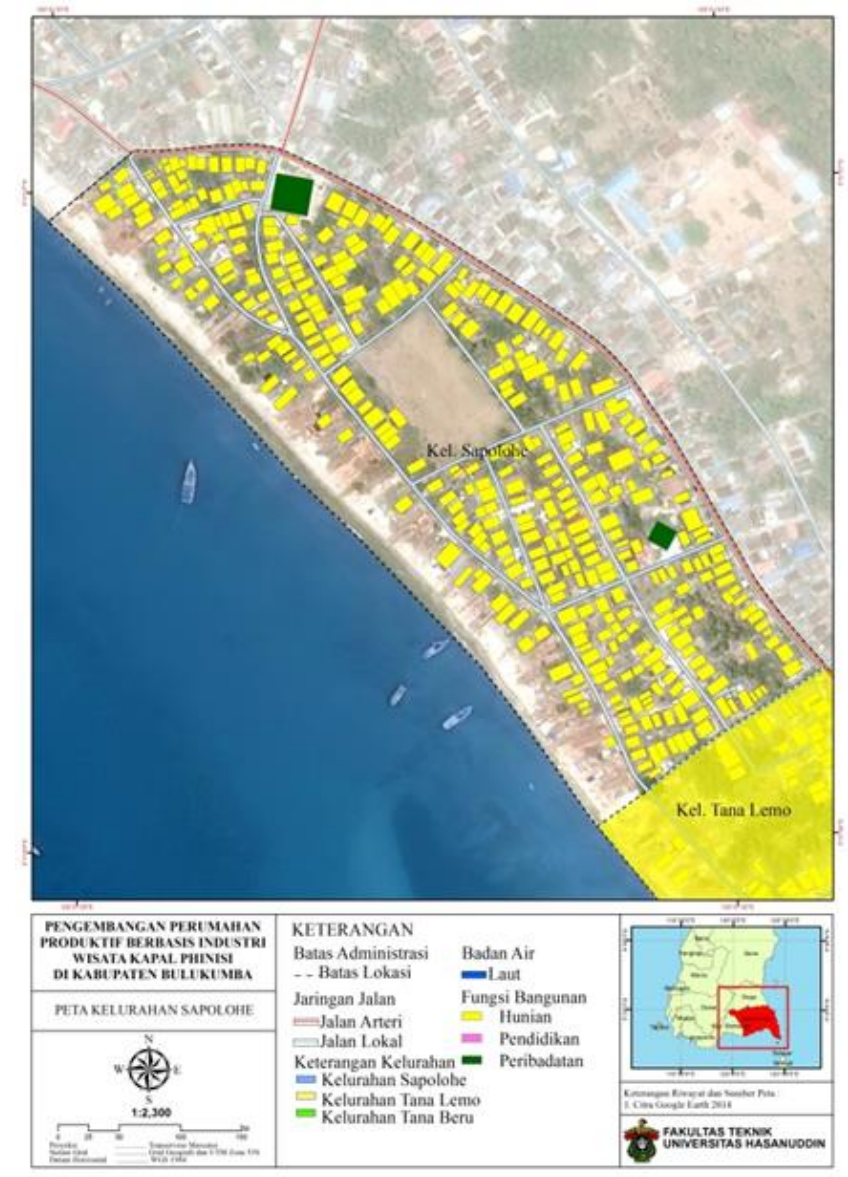

Gambar 2. Lokasi penelitian 1 Kelurahan Sapolohe

Lokasi penelitian 1 merupakan Kelurahan Sapolohe, yang berada di Kawasan Industri pembuatan kapal phinisi di Bontobahari. Total jumlah populasi sebanyak 101 unit dan jumlah sampel sebanyak 60 unit. Lokasi ini merupakan sentral tempat memperbaiki kapal phinisi jika ada yang rusak. 


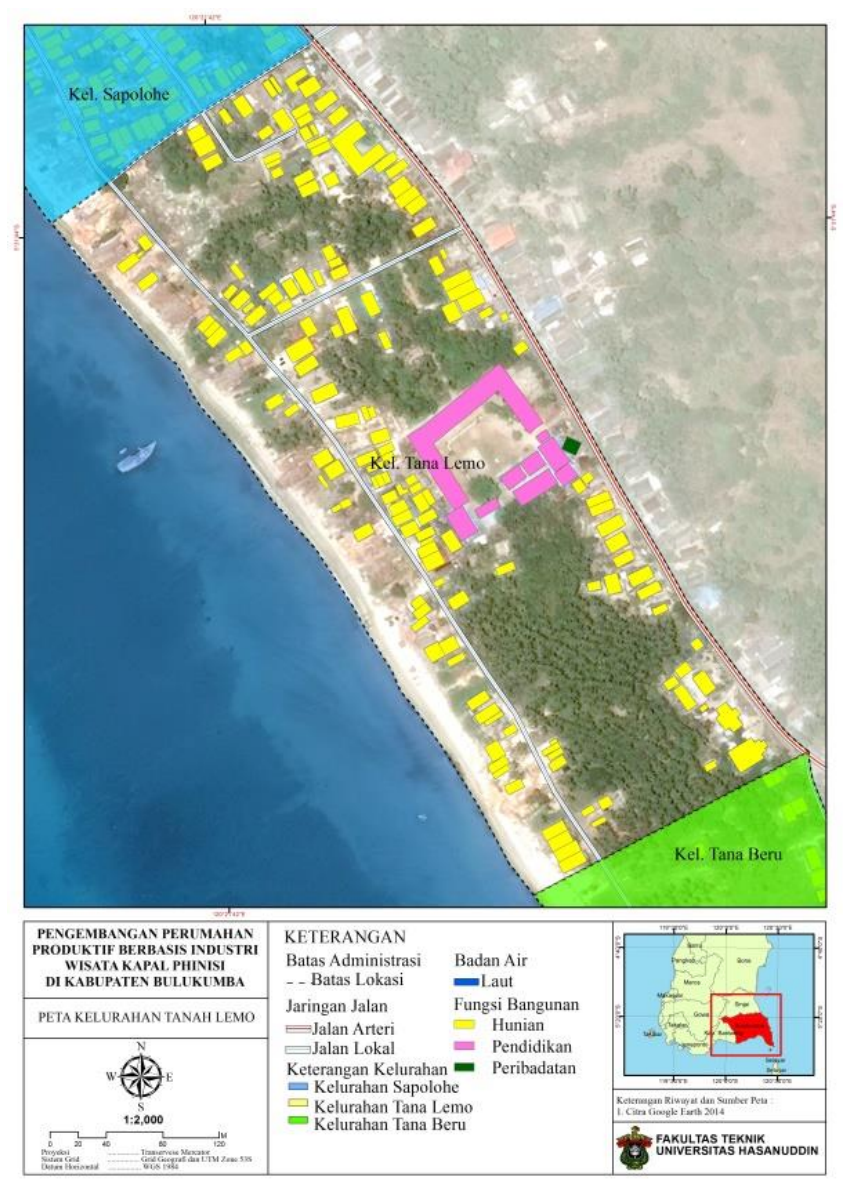

Gambar 3. Lokasi penelitian 2 Kelurahan Tanah Lemo

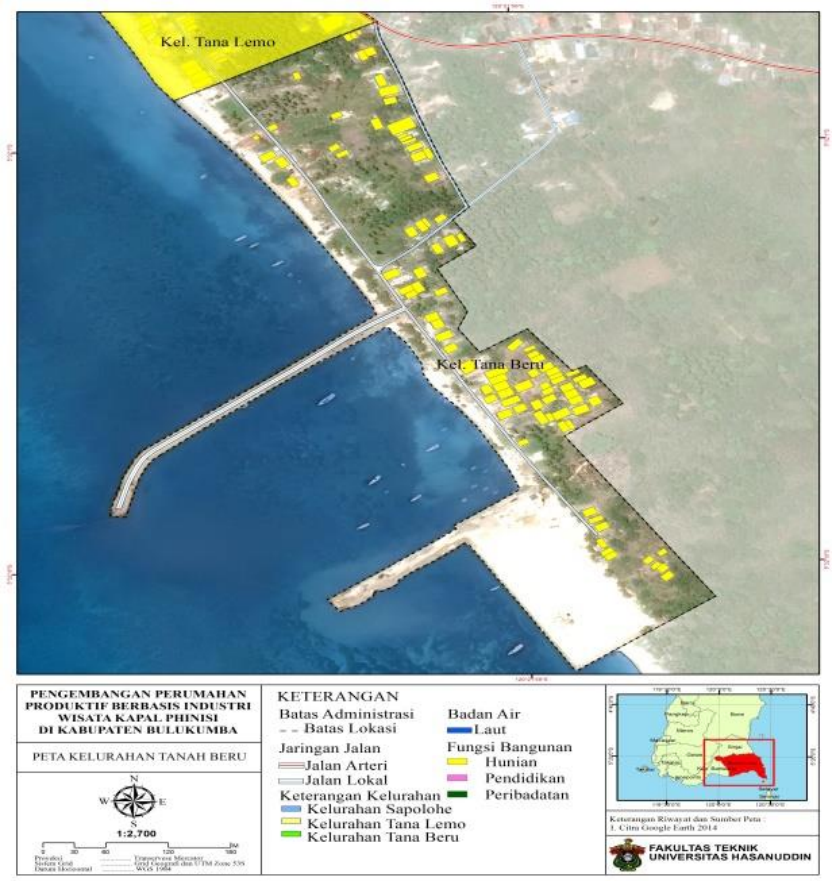

Gambar 4. Lokasi penelitian 3 Kelurahan Tanah Beru
Lokasi penelitian 2 merupakan Kelurahan Tanah Lemo, yang berada di Kawasan Industri pembuatan kapal phinisi di Bontobahari. Total jumlah populasi sebanyak 93 unit dan jumlah sampel sebanyak 55 unit. Lokasi ini merupakan area pendidikan, karena terdapat sekolah.

Lokasi penelitian 3 merupakan Kelurahan Tanah Beru, yang berada di Kawasan Industri pembuatan kapal phinisi di Bontobahari. Total jumlah populasi sebanyak 78 unit dan jumlah sampel sebanyak 46 unit. Lokasi ini merupakan area nelayan. Banyak penduduk yang bekerja sebagai nelayan, hal ini juga disebabkan karena di kelurahan Tanah Beru terdapat area dermaga, tempat pendaratan ikan.

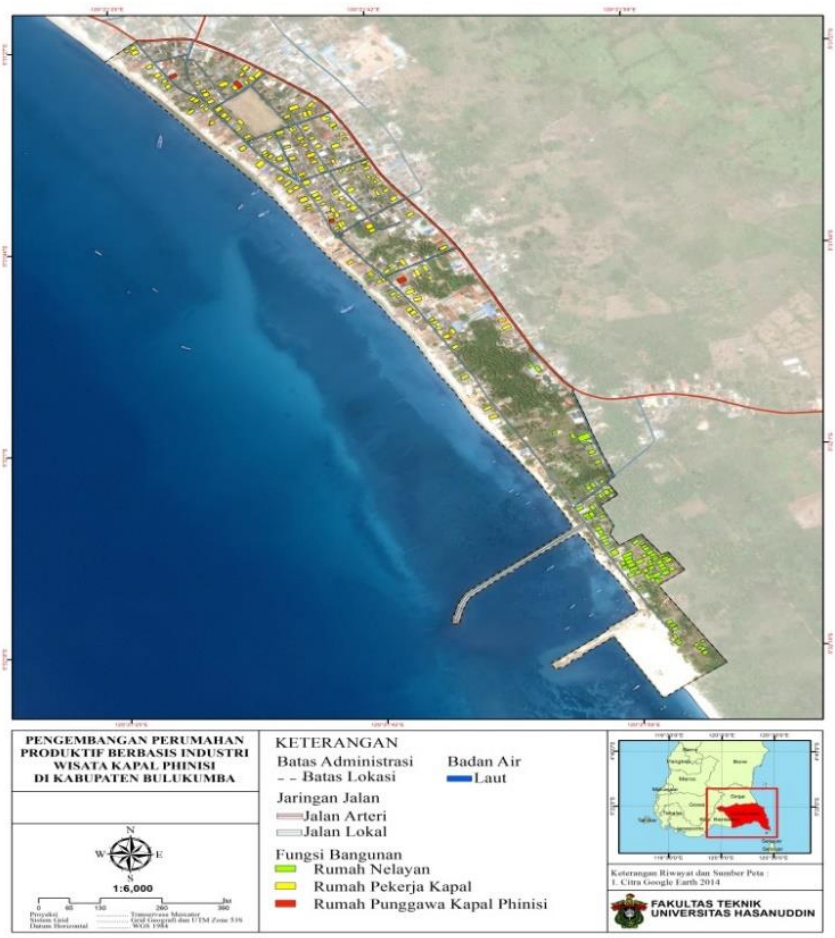

Gambar 5. Letak rumah pengrajin kapal, punggawa kapal dan nelayan yang berada di kawasan industri pembuatan kapal phinisi

Gambar 5 memperlihatkan letak rumah pengrajin phinisi beserta rumah punggawa pada kawasan industri pembuatan kapal phinisi, yang berada di Kecamatan Bontobahari. Rumah pengrajin phinisi tersebar di 3 lokasi penelitian dengan total 138 rumah yang bekerja sebagai pengrajin phinisi. 


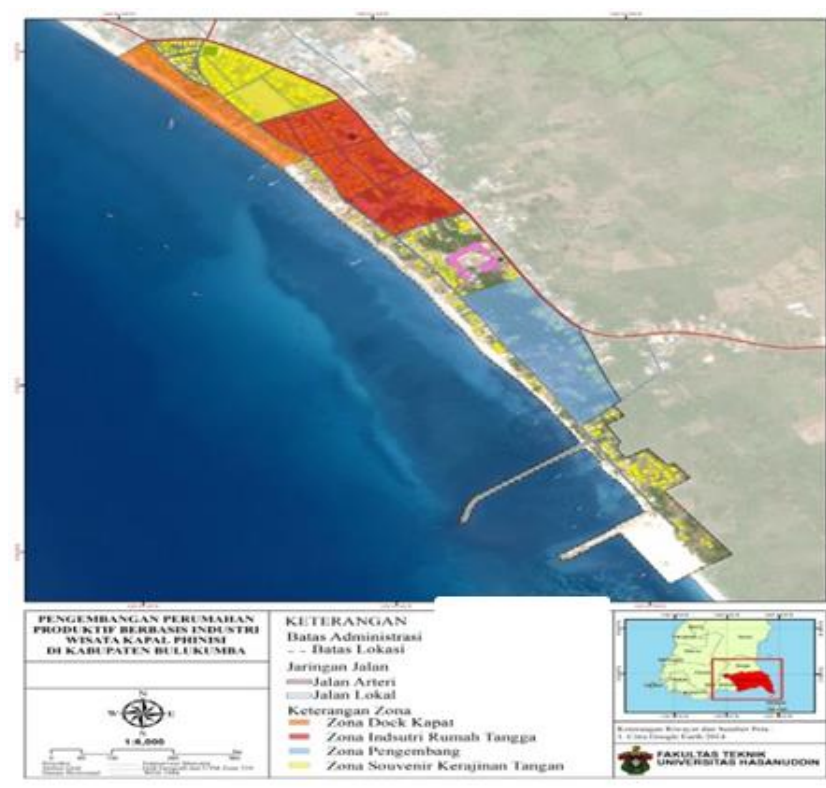

Gambar 6. Zonasi pada kawasan industri pembuatan kapal phinisi

Gambar 6 merupakan pembagian zona pada kawasan industri pembuatan kapal phinisi, terbagi atas 5 zona yaitu; zona dock kapal, zona industri rumah tangga, zona souvenir kerajinan tangan dan zona area pengembangan kawasan.

2.3. Objek Penelitian, Kasus Amatan dan Narasumber

Objek penelitian adalah seluruh rumah dalam Kawasan Industri Pembuatan Kapal Phinisi di Kecamatan Bontobahari Kabupaten Bulukumba, baik itu rumah panggung dan non panggung. Khususnya pada rumah panggung tradisional bugis. Rumah panggung dipilih karena nilai tradisional masih kental pada kawasan industri pembuatan kapal phinisi.

Proses pengambilan sampel menggunakan metode simple random sampling. Penentuan jumlah sampel yang diambil dalam studi ini ditentukan dengan rumus slovin dan diperoleh jumlah sampel yaitu 162 unit rumah. Selanjutnya sampel dibagi menjadi 3 bagian, penentuan sampel pada lokasi adalah memberikan kesempatan yang sama pada populasi untuk dijadikan sampel.

\subsection{Pengumpulan Data}

Metode pengumpulan data adalah (1) Observasi langsung dengan membuat catatan, mengambil gambar rumah, (2) Membagikan kuesioner.

\subsection{Analisis Data}

Analisis data yang digunakan adalah deskriptif, eksploratif, dan komparatif yang sifatnya memaparkan dan menjelaskan temuan hasil penelitian. Data yang telah diperoleh di lapangan kemudian dianalisis dengan menggunakan analisis komparatif dan analisis secara deskriptif.

\section{Hasil Penelitian}

Hasil penelitian menunjukan bahwa terdapat 26.5\% rumah panggung kolong tidak terbangun yang dapat merupakan objek wisata dengan total 43 unit rumah. Sedangkan terdapat $51.9 \%$ rumah panggung kolong terbangun untuk tempat berusaha juga dapat merupakan objek wisata dengan total 84 unit rumah.

Sedangkan rumah lainnya yang tidak dapat dijadikan objek wisata disebabkan karena nilai tradisionalnya sudah hilang yaitu terdapat $21.6 \%$ atau 35 unit rumah.

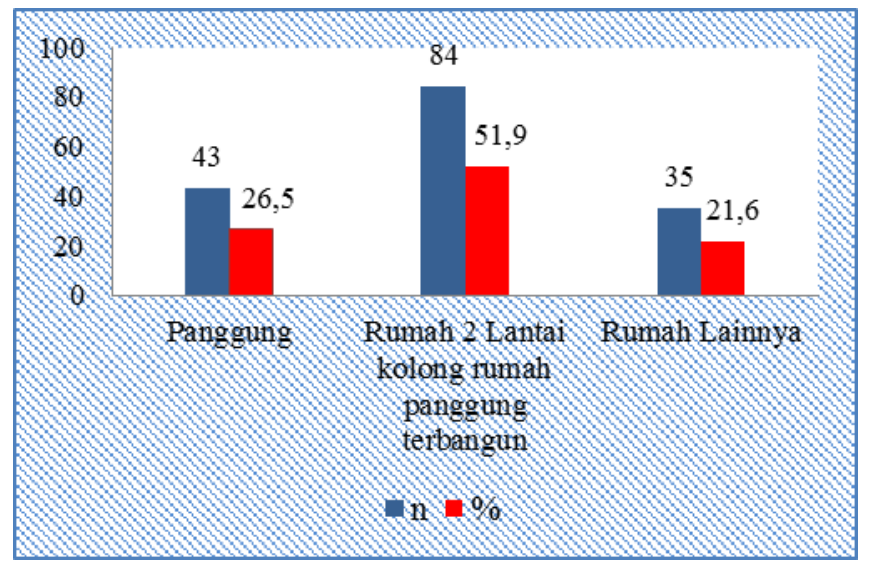

Gambar 7. Persentase diagram batang rumah panggung tradisional dan non panggung pada kawasan industri pembuatan kapal phinisi

Tabel 2 memperlihatkan hasil analisis jenis material rumah panggung dan non panggung yang digunakan pada kawasan industri pembuatan kapal phinisi. Rumah yang berada pada kawasan industri pembuatan kapal phinsi, kebanyakan menggunakan material papan sebanyak 45.7\%, dan hanya $3.7 \%$ menggunakan material batu bata, selebihnya rumah didalam kawasan hanya 
menggunakan material seng $34.0 \%$ dan menggunakan bambu sebanyak $16.7 \%$.

Sedangkan pada tabel 2 memperlihatkan jenis material lantai rumah tradisional yang berada pada kawasan industri pembuatan kapal phinisi. Ada rumah menggunakan material papan, beton, dan juga menggunakan material kayu. Bentuk rumah panggung lebih dominan menggunakan material kayu. Disebabkan karena kayu merupakan bahan tradisional dan bahannya mudah didapatkan di Kabupaten Bulukumba.

Tabel 2. Analisis jenis material dinding rumah

\begin{tabular}{llll}
\hline No. & \multicolumn{1}{c}{$\begin{array}{c}\text { Jenis Material } \\
\text { Rumah }\end{array}$} & \multicolumn{1}{c}{ n } & \multicolumn{1}{c}{$\%$} \\
\hline 1 & Papan & 74 & 45.7 \\
2 & Seng & 55 & 34.0 \\
3. & Bambu & 27 & 16.7 \\
4. & Batu Bata & 6 & 3.7 \\
\hline Total & & $\mathbf{1 6 2}$ & $\mathbf{1 0 0}$ \\
\hline
\end{tabular}

Tabel 3 Analisis jenis material lantai rumah pada kawasan

\begin{tabular}{llll}
\hline No. & $\begin{array}{c}\text { Jenis material } \\
\text { lantai }\end{array}$ & n & \% \\
\hline 1. & Papan & 83 & 51.2 \\
2. & Tegel & 17 & 10.5 \\
3. & Semen & 62 & 38.3 \\
\hline Total & & $\mathbf{1 6 2}$ & $\mathbf{1 0 0}$ \\
\hline
\end{tabular}

Dari hasil analisis tabel 3 diatas Jenis material lantai rumah yang kebanyakan dipergunakan pada kawasan industri pembuatan kapal phinisi adalah jenis papan sebanyak 83 unit rumah atau $51.2 \%$, sedangkan yang menggunakan material tegel hanya 17 unit atau $10.5 \%$. Ini membuktikan bahwa rumah yang berada pada kawasan industri pembuatan kapal phinisi masih merupakan rumah tradisional.

Hasil analisis pada jenis atap, beberapa rumah pada Kawasan Industri Pembuatan Kapal Phinisi, hanya sebagian besar rumah memakai jenis atap genteng sekitar $23.5 \%$ atau sebanyak 38 unit rumah, sementara kebanyakan rumah memakai atap seng sebanyak 84 unit atau sekitar 51.9\%. Hal Ini menyatakan atap seng sangat identik dengan rumah panggung tradisional bugis, sedangkan sisanya $4.3 \%$ sebanyak 7 unit yang masih menggunakan atap rumbia.

Di Kawasan industri pembuatan kapal phinisi rumah tradisional kebanyakan penduduk memakai bentuk perisai tradisional bugis dari pada memakai bentuk pelana bugis. Alasan yang paling mendasar adalah karena nilai tradisional dari atap perisai bugis masih ada.

Analisis beberapa rumah pada Kawasan Industri Pembuatan Kapal Phinisi, sebagian bentuk atap rumah lebih dominan kebentuk perisai sebanyak 87 unit persentasi sekitar 53.7\%, sedangkan sebanyak 16 unit sekitar $9.9 \%$ yang menggunakan bentuk plat beton. Bentuk Limas tidak terdapat pada Kawasan Industri Pembuatan Kapal Phinisi ini, model atap pelana cuman $36.4 \%$ atau sebanyak 59 unit rumah. Kawasan Industri pembuatan kapal phinisi biasa dijadikan objek wisata dikarenakan masih menganut nilai tradisional dan budaya leluhur.

Tabel 4. Bentuk atap rumah pengrajin phinisi

\begin{tabular}{llll}
\hline No & \multicolumn{1}{c}{ Kriteria } & n & \% \\
\hline 1 & $\begin{array}{l}\text { Perisai } \\
\text { (tradisional bugis) }\end{array}$ & 87 & 53.7 \\
2 & $\begin{array}{l}\text { Pelana } \\
\text { (non tradisional) }\end{array}$ & 59 & 36.4 \\
3 & Beton & 16 & 9.9 \\
\hline \multicolumn{1}{c}{ Jumlah } & $\mathbf{1 6 2}$ & $\mathbf{1 0 0}$ \\
\hline
\end{tabular}

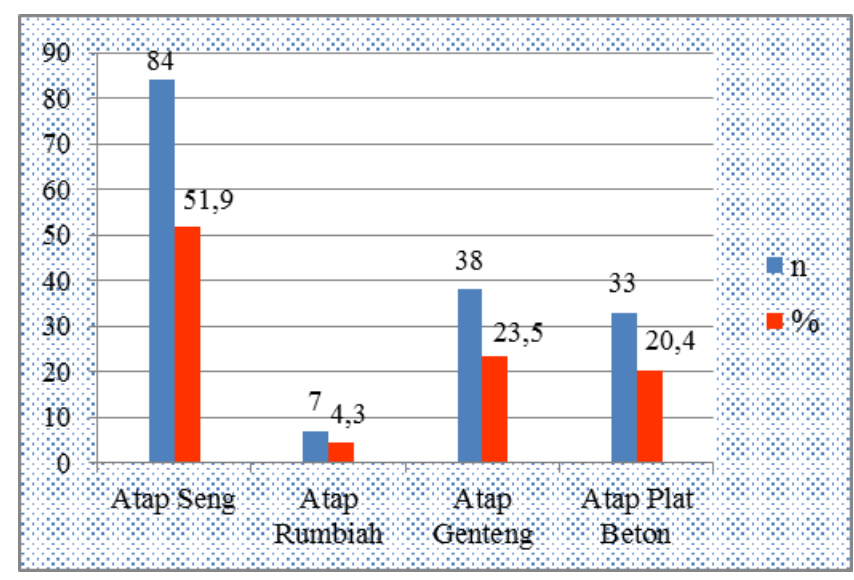

Gambar 8. Persentase jenis atap rumah

Analisis dari Tabel 5 menyatakan bahwa elemen pada rumah tradisional di kawasan pembuatan kapal phinisi yang penggunaannya masih dalam bentuk aslinya adalah elemen atap yaitu sekitar $52.5 \%$ elemen yang mengalami perubahan yang signifikan adalah organisasi ruang sekitar $6.2 \%$ dari total sampel $100 \%$. Sedangkan elemen tangga yang mengalami perubahan sekitar $19.8 \%$, dan jendela $21.6 \%$. 
Ini membuktikan bahwa penggunaan elemen atap pada rumah tradisional tidak pernah di perbarui atau masih tetap dalam bentuk aslinya. Dan menandakan bahwa elemen atap tidak banyak diubah dikarenakan fungsi tradisionalnya akan hilang.

Kebanyakan rumah warga yang berada dalam kawasan industri pembuatan kapal phinisi mempunyai jenis atap seng, dan model rumah panggung tradisional sesuai dengan hasil analisis kuesioner.

Tabel 5. Analisis elemen rumah tradisional

\begin{tabular}{cccc}
\hline No. & Elemen Rumah panggung & $\mathbf{n}$ & $\mathbf{\%}$ \\
\hline 1. & Tangga & 32 & 19.8 \\
2. & Atap & 85 & 52.5 \\
3. & Organisasi Ruang & 10 & 6.2 \\
4. & Jendela & 35 & 21.6 \\
\hline & Total & $\mathbf{1 6 2}$ & $\mathbf{1 0 0}$ \\
\hline
\end{tabular}

\section{Pembahasan}

Penelitian ini memperlihatkan bahwa karakteristik yang berada pada kawasan industri pembuatan kapal phinisi masih didominasi dengan karakter tradisional. Dari total sampel 162 sebanyak $51.9 \%$ menggunakan rumah panggung tradisional bugis yang kolong rumahnya terbangun. Begitu juga dengan hasil analisis pada material rumah yang dipakai pada kawasan industri pembuatan kapal phinisi, sekitar $45,7 \%$ masih menggunakan material papan pada rumahnya. Jenis material papan ini merupakan material yang sama pada pembuatan kapal phinisi, yaitu kayu yang didatangkan dari Kendari, maupun Jayapura.

Hasil analisis pada material lantai yang dipergunakan penduduk kawasan industri pembuatan kapal phinisi adalah sebanyak 83 unit atau $51.2 \%$ juga menggunakan lantai papan, sedangkan hanya $10.5 \%$ yang menggunakan lantai tegel. Itu menandakan karakteristik kawasan perumahan pengrajin phinisi masih tradisional.

\section{Kesimpulan dan Saran}

Karakteristik perumahan dan lingkungan pada kawasan industri pembuatan kapal phinisi di Tanahberu Kabupaten Bulukumba yang dapat mendukung kegiatan wisata adalah rumah panggung yang berkarakter tradisional bugis, dapat dinilai dari ciri atap, pintu, jendela (to see). Atap rumah yang berada pada kawasan industri pembuatan kapal phinisi ini dominan dengan atap perisai tradisional bugis. Pada kawasan industri pembuatan kapal phinisi elemen atap kebanyakan penduduk sekitar tidak merubahnya, ini dikarenakan elemen atap merupakan elemen yang paling dominan pada nilai tradisional.

Begitu juga dengan jenis material rumah yang berada pada kawasan industri pembuatan kapal phinisi. Baik itu pada material atap,dinding dan lantai, semuanya masih memilih dengan nilai tradisional.

\section{Ucapan Terimakasih}

Penelitian ini dapat diselesaikan atas partisipasi aktif berbagai pihak. Secara khusus terimakasih kepada Ibu Prof. Dr. Ir. Shirly Wunas, DEA , Ibu Dr. Mimi Arifin, M.Si Dosen-dosen penguji Bapak Prof. Dr. Ir. Ananto Yudono, M.Eng, Ibu Ir. Hj. Idawarni Asmal, MT dan Ibu Ir. Ria Wikantari Rosalia, M.Arch., Ph.D atas bantuan dan bimbingannya. Berterimakasih kepada rekan-rekan mahasiswa khususnya di Teknik PWK dan mahasiswa program pascasarjana 2015 yang selalu memberi dukungan dalam proses penelitian dan penulisan ini hingga selesai.

\section{Referensi}

[1] Hardiman, G., Pengamatan Pengembangan Ruang Publik di Tepi Pantai dari Beberapa Kota di Pulau Sulawesi dari Aspek "Tropis Lembab". Seminar Nasional Peran Arsitektur Perkotaan dalam Mewujudkan Kota Tropis., 2008. -(-): p. 1-8.

[2] Purnamasari, A., Kajian spasial Ruang Publik (Publik Space) Perkotaan untuk aktifitas demonstrasi mahasiswa di Kota Makassar. Jurnal Institut Teknologi Sepuluh Nopember Surabaya, 2010: p. 27-36.

[3] Rijal, S., Kebutuhan Ruang Terbuka Hijkau di Kota Makassar Tahun 2017. Jurnal Hutan dan Masyarakat, 2008. III No.1 Mei 2008(Green open space): p. 65-77.

[4] Amri, Evaluasi ketersediaan Ruang Terbuka Hijau di Kompleks Perumahan Bumi Permata Sudiang Kota Makassar. Prosiding Hasil penelitian Fakultas Teknik 2011. 5: p. 1-8.

[5] T.T, S. and H. Purnaweni, Kearifan Lokal dalam melestarikan mata air (studi Kasus di desa 
Purwogondo, Kecamatan Boja, Kabupaten Kendal). Jurnal Ilmu Lingkungan, 2011. 9(2): p. 6.

[6] Lisbijanto, H., Kapal Pinisi. Graha Ilmu Buku, 2013: p. VIII+44.

[7] Amar, S., Asal Usul Keahlian Pembuatan Perahu Phinisi di Tanah Lemo Bulukumba. Jurnal EducatiO, 2013. Vol. 8 No. 2, (Pembuatan Perahu Phinisi di Tanah Lemo Bulukumba): p. 151-167.

[8] Caro, P., Phinisi Nusantara, Mangarungi Lautan 11.000 Mil Jakarta-Vancouver, . Buku Jakarta: Krisna Press., 1988(Phinisi Nusantara).

[9] Nooteboom, Perihal Perkapalan dan Pelayaran di Indonesia. Jakarta: De Moderne Boek Handel., 1951. 2(Perkapalan dan Pelayaran di Indonesia).

[10] Mubyarto., Peluang kerja dan Berusaha di Pedesaan. Journal FEUGM Yogyakarta, 1985.

[11] Lantara, D., Proses Produksi Pembuatan Kapal Layar Phinisi untuk Meminimalkan Waktu Produksi dengan Model PERT (Programming Evaluation dan Review Technique) Jurnal Energi dan Manufaktur, 2014. Vol.7, No.1,(Proses produksi kapal layar phinisi): p. 1-118.

[12] M.Toriq, Dewa Ruci. Buku Jakarta.CV.Ghina Walafafa, 2007.

[13] Suprijanto, I., Rumah Tradisional Osing Konsep Ruang Dan Bentuk. Dimensi Teknik Arsitektur 2002. Vol. 30, No. 1,(Dualitas dan centralitas Tikel Balung, Baresan dan Cerocogan.): p. 10-20.

[14] Wunas, S., Pengembangan Konsep Multi Fungsi Lahan di Kawasan Sub-Urban Makassar. Prociding 2011. 5 (Pengembangan Sarana dan Prasarana terhadap Kegiatan Sosial Ekonomi Masyarakat): p. 1-10.
[15] Minderop and Albertine., Psikologi Sastra: Karya Sastra, Metode, Teori Dan Contoh Kasus. Yayasan Pustaka Obor Indonesia., 2011(Contoh Kasus).

[16]Silas, J., Home Based Enterprises. Jurnal Alur Permukiman Kota dan Lingkungan, Pasca Sarjana Institut Teknologi Sepuluh Nopember, Surabaya., 1999.

[17]Amos, R., House Form and Culture. Journal Englewood Cliffs, Prentice Hall, New York., 1969(Form and Culture).

[18] Bonnieta Franciska and L.K. Wardani, Bentuk, Fungsi, dan Makna Interior Rumah Adat Suku Tolaki dan Suku Wolio di Sulawesi Tenggara. JURNAL INTRA Vol. 2, No. 2, (2014) 688-701, 2014. Vol. 2(Bentuk, Fungsi dan Makna, Rumah Adat): p. 688-701.

[19] Budihardjo, E., Jatidiri Arsitektur Indonesia. Jurnal PT Alumni, Bandung., 1996: p. 5-8.

[20] Sastrawati, I. and S. Wunas, Pengembangan rumah panggung swadaya tahan bencana melalui pemberdayaan masyarakat di kawasan pesisir sulawesi selatan. Penelitian hibah kompetitif penelitian sesuai prioritas nasional (hibah penelitian strategis nasional) 2009.

[21] Widyastomo, D., PERUBAHAN POLA PERMUKIMAN TRADISIONAL SUKU SENTANI DI PESISIR DANAU SENTANI. Jurnal Permukiman, 2011. Vol. 6 No. 2(Perubahan, pola permukiman, tradisional, suku Sentani, Danau Sentani): p. 84-92. 